\title{
Putting the Focus on Children as Deliverers of New Technologies
}

\author{
Anne Bamford
}

\begin{abstract}
In this interview, professor and researcher Anne Bamford describes how she initially became interested in virtual learning via cyberbullying, particularly how image manipulation affects young people's perceptions. Next, she discusses her European-wide study on "active 3D" in the classroom, which showed that the more control children took for their own learning, the better the results were. She argues that student involvement and engagement in implementing new technologies is critical for successful virtual learning in schools. Finally, she urges educators to "use the technology where it's going to have the most impact" and not to "put it just for the sake of putting it in the curriculum."
\end{abstract}

You've been studying the uses of virtual learning environments for a long time, can you explain how you first got involved in this area and why?

My first foray into the area of virtual worlds was via some research I did into cyberbullying. I was interested in how teenagers' perceptions were being changed by their interactions in an online environment. I was particularly focused on the way in which image manipulation causes young people to see their identities quite differently. One thing led to another because what happened was that to be able to do the research that I wanted to do around cyberbullying and the impact of image manipulation on young people's perceptions, I wanted to be able to have access to the Photoshop software, which at the time was only a professional-level software-it wasn't available for general classroom usage. I wanted to see whether young people's perceptions would change when they had the opportunity to manipulate their own images and could understand what was happening in a virtual environment. That really led me on to using that software and using that software with young people. There is a quite funny story really in terms of that because when I first approached Adobe to be able to have the permissions to use it, they said: "Well, it's not going to be relevant at all to education ... young people won't know how to use it ... it's a professional-level software." And, of course, within an hour, the young people could not only use it, but they could do all these things that the company hadn't even imagined were possible. But the long and the short of that is that resulted in a lot of research I did around visual literacy, which led me into the virtual learning world, but it was very much based on how visual learning affects us both emotionally as learners, but also obviously in terms of the educational impact on learning.

In 2011, you did a large study of 3D learning and its impact on pupils' learning across seven European countries. Can you describe this study and its findings?

It was actually across 10 countries, but we reported it across seven countries because in three of the countries it was done internally-it wasn't externally verified. Basically, it was looking at what is the impact of "active 3D," which is a type of 3D where the image "comes out" at the child, as opposed to 
3D which exists within a screen - it was active 3D using 3D glasses. The study was across volunteer classes; the teachers volunteered to be part of this study. But apart from that, the schools weren't selected on the basis of whether they were very technical or not. It was simply on those schools that wanted to be part of this study, and it was a traditional control-group based study. It was all working in the science area. The theme was on "My Body" or "The Human Body," and it was mainly done with pupils aged between 10 and 14 . The reason we chose that topic was because it was a topic that all schools, regardless of language, study that topic, roughly about that time, so it felt relevant across cultural boundaries. The study was a traditional study in that the participants were all pre-tested, then they were post-tested after six to eight weeks of the unit involving the 3D. The school had to have one class that used the 3D and another class that didn't use the 3D, but had everything else the same-obviously, they didn't have the teacher the same-in other respects, they had the same situation. We researched the group across time and really looked at the impact on a range of different things: attention span, test scores, learning, communication in the classroom, talking in the classroom, and so on.

As you look back since then, what would you suggest are the most important ingredients for successful virtual learning in schools, and why?

The results of that study were quite interesting because the results showed that, not only did children achieve better test scores, but their percentage of improvement was much higher. Surprisingly, in the control groups: only just over $50 \%$ of the children improved at all. And that's quite worrying if you think of eight weeks of learning and very little improvement. I suppose there is a general point for education about the importance of pre-testing children because I think that had we not pre-tested, we may have assumed quite different things. I think the use of pre-testing is a more general conclusion for education. But in terms of the specifics around what works with the introduction of technology, I think one of the key ingredients is engagement of the children or the pupils in the implementation of the technology because teachers struggle to have the time-and also the confidence or the perception of confidenceto often launch into new technologies.

We found that the children very quickly took control of running the 3D learning. In fact, the more the children took control, the better the results were in the school; it was actually the overriding findings. For instance, in one of the Italian schools, there was very limited technical ability and very limited technical resources in the school. For example, the school didn't have Internet that was reliable enough to use in an educational context. So, their success was greater, if not more so, than some of the other schools were there was a lot higher levels of technical proficiency because the children took control of it. And in the children's hands, they were very adventurous and used it a lot. I think a very strong finding was when we implement new technology in an educational context, we need to focus much more on children being the deliverers of the new technology-and not the teachers. The teachers certainly did a lot of work around mediating the content and making the lessons interesting, but we didn't rely on the teachers to actually deliver the technology. And that seemed to have a considerable benefit. The research showed the value of pre-testing and post-testing children so you can really measure change, but the overarching conclusion for education and the implementation of technology was "give it to the kids" — don't "give it to the teachers." 
Initially, when I began that study, I was quite concerned that it would have a negative effect on the children's communication in the classroom. In other words, they put on the 3D glasses and it would cause them to not communicate, and that would stifle learning. In fact, we found a really interesting thing: that as soon as they put the $3 \mathrm{D}$ glasses on, they communicated even more. And then after the 3D experience, they continued to communicate even more! Contrary to my belief, and what people had said around technology perhaps limiting classroom communication, it really boosted classroom communication. The effect of it lasted a long time after the technology stopped. You could take off the glasses and turn off the 3D, and the level of on-task communication continued to increase. It sort of had a flow-on effect, which was a surprising ending.

Do you have an idea why that happens?

My view was the children became more on-task, and also that the experience was so vivid that, even despite themselves, they found themselves asking questions and being interested. Remember, I said they were 10- to 14-year-olds ... so there is that general thing amongst teenagers to not ask questions and to be a bit cool ... it seems that the experience was so strong, it broke through that. The other aspect to it which was particular to the $3 \mathrm{D}$, is when you were using active $3 \mathrm{D}$, it was impossible for the teacher to stand at the front of the room, because otherwise the teacher didn't see it. The teacher had to position him or herself amongst the pupils and I think that physical movement of the teacher also changed the dynamics of the classroom, which meant more questions were asked as well. A combination of the excitement of the experience dragged the children in even if they were trying to "be cool" and also that when the teacher moved themselves into the position with the children, the dynamics in the classroom changed, which also meant that there was a different flow of conversation. I was surprised it continued to increase ... so it sort of stimulated it.

Where do you think virtual learning is heading in the future? What platforms are the best?

I think there's a lot of potential for virtual learning that's not been effectively mined. We have a huge capacity to do a lot more than we do-particularly in the British context where I am at the momentthere's a huge potential for virtual learning where we have shortages of qualified teachers. We're desperately short of teachers in London and I think that that's an opportunity. There's also an opportunity to bring to young people a breadth of topics and subjects and expertise that we couldn't otherwise doand also do things that we couldn't otherwise do. For example, in the virtual world, kids can split atoms and all of these things that they can't ever do in the realities of the classroom. While I don't think it's a substitute for classroom experiences, it's a very powerful adjunct.

There is a lot more capacity for global learning. One of the interesting findings from that European study was that many of the teachers who met virtually through the process of being participants in the research have continued on that meeting, that sharing of resources, and the sharing of information. I think that would become a really valuable thing, so we become less centered on just our school and just our country, and we're more proactive in an international sense. In countries where there's a lack of teacher training and teacher education, it could be used to also develop the workforce and develop knowledge in the workforce. 
If you were designing a school from scratch, what would you do to make certain that successful virtual learning is an integral part of the curriculum?

Interesting you ask that question because I was asked a question sort of similar in an interview relatively recently and they asked me, "What do you think the school of the future might look like?" And in that I feel, "perhaps there won't be a school at all," and they said, "What piece of technology might lead to the most change?" And I said, "perhaps the Google self-driving cars would" because I could put the pupils in cars that would then drive off to museums and galleries and concerts, and so on to see the world. I don't really know, but I think that it's got to be a collaborative space, so the design of the school, if you're going to have a physical school, has to maximize the opportunity for collaboration between subjects, between staff, and between pupils. It has to be based much more on pupil-led learning than we've currently got. The role of the teacher is going to change significantly in the future, and I don't think the current models of teacher education adequately prepare people for this quite different role. The role of the teacher will be still important and probably even more important, and it will be a much higher-level role because it will require much more critical and reflective thinking on behalf of the teacher. But I don't think we're adequately preparing teachers for the future. We need quite different competencies in the competencies we've got.

In terms of a physical or virtual environment, I would like to see content much more freely accessible to people. Content is still quite expensive to schools. Also, we have to have much more plug-in-and-go technology. Obviously, the Cloud is part-way to that because we can't be dependent on continually updating hard resources-because that's just too expensive for most education systems. It has to be something that's delivered, like electricity or gas, that's just there, and we sort of plug in and go. I think that that will be the future and I think we have to stop having technologies that imitate old ways of working. For example, I'm not a great fan of the electronic white board-and I know that upsets some people when I say it—but it's because I think it reinforces a way of teaching that wasn't a very effective way of teaching and learning. We have to not just use technology to sort of replicate an existing system, we have to think what can technology do better. And, perhaps as I've said, it might a self-driving car ... you can put the children in it and send them off to the museum to learn ... that might be a great revolution because the cost of buses prevents people from going to the museum. It's about thinking outside the box on how to use technology in the classroom.

What advice do you have for teachers and school leaders embarking on virtual learning?

I've probably hinted at it already, but the first one I would say is: "get your children involved—get the young people involved" because the so-called "digital natives" are better than we are at using this in a very intuitive way. That would be the first thing I suggest is make sure that you straight away give it across to the young people to see what they can do with it. The other thing teachers need to do is think about assessment because you need quite different models of assessment. I'm a big fan of tracking children's learning and pre-testing as we really need to know what children know before we begin to teach and also how our teaching changes what a child knows or can do. 
If we're not very careful—we've all done it ourselves when we're searching on the Web or somethingyou can spend several hours, and you haven't really achieved much at the end of it. It hasn't really had a big impact on your learning ... it hasn't changed the way you think ... it hasn't been critical ... it's not very high level. As we look at new forms of learning and the use of technology, we have to make sure our assessment and evaluation tools are up to the job because they have to be able to see that we're really learning. You can't have children wasting time and not actually learning. How do we know ... if doing 3D or whatever ... for 10 minutes or half an hour ... how has that really changed the way they learn and do we have the tools in place to be able to track their learning?

There is some interesting research out at the moment ... changes in neuroscience, in data tracking, in rich data-those sort of things might give us a key, but I think we need to develop better tools. The teachers embarking on this need to be thinking about "assessment" right from the very start. What are we trying to learn? How will we know if the children are learning it? And to be honest, if they can learn it better with a pencil and paper, then give them a pencil and paper! Use the technology where it's going to have the most impact. Don't put it just for the sake of putting it in the curriculum, which is sometimes what you see.

Do you think professional development is necessary for teachers embarking on this kind of project?

That's a really interesting question because based on the findings of the research that I've done, I'm looking at that quite differently. We've recently conducted some research with Microsoft where, quite deliberately, we invited the children to professional development and we said to the teachers, "Sit over there at the table. There are some laptops if you want to do it, but basically relax. Have a coffee, enjoy some nice food. We don't care if you don't do anything today if you just relax." It was interesting because the teachers became much more interested and were going to the children to try and learn the work. I think flipping the focus around, perhaps too much emphasis is being placed on professional development of teachers, and insufficient effort being placed on the development of children to lead learning. I'm trying to flip it round the other way in creating children as learning ambassadors and saying to the teachers: "You work really hard. Just relax. Have a coffee. Chill." And it actually has a reverse psychology thing that they become really interested in wanting to learn. They're sort of fighting to learn, rather than being disenfranchised, sitting in the back of some professional development session, not really caring what goes on. I'm turning it around a little bit- I'm not quite sure of my answer to that one yet.

Can you describe something you saw that was very interesting when children take charge of their learning?

I want to give an example from Italy because it was quite moving when it actually happened. The children were from a "Roma" community. Traditionally, they're referred to as a "gypsy" community. The pupils were in a quite deprived area in Rome and the teacher was absolutely amazed because one of the Roma boys had gone home after seeing the 3D heart, which was pumping and beating in front of him. $\mathrm{He}^{\prime} \mathrm{d}$ gone home and out of a plastic drink bottle and some straws and things, he'd created his own model of the heart and then he brought it into school the next day and was explaining to the children how it worked. The teacher was just absolutely amazed because she said, "He's never really engaged in 
anything. And not only is he engaged in it, but he's gone with his quite limited resources and created this, and then been willing to share it back into the classroom." I think that's incredibly powerful as a way. We also had children in Sweden, which when it was lunch time, they didn't want to stop. In Greece, the children themselves were developing their own 3D content ... they were starting to use $3 \mathrm{D}$ cameras. When you leave it with them, they do so much more than your ambition that you could have set for the program ... when they get enthusiastic about something and when you give them ownership of it.

Do you have any other comments that you would like to add?

I think the key things are in teacher education for the future, around assessment and evaluation and how we get much smarter in what we do there. I think it is about the role of the teacher changing and giving ownership to the children; and if you don't, you're always going to be behind the development of things. You have to think quite differently than we currently do.

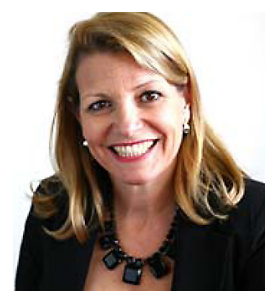

Anne Bamford is currently Director of the International Research Agency and Director of the Education Commission and a former Professor at the University of the Arts London. Anne has been recognized nationally and internationally for her research in arts, education, emerging literacies, and visual communication. She is an expert in the international dimension of education and through her research, she has pursued issues of innovation, social impact, and equity and diversity. A World Scholar for UNESCO, Anne has conducted major national educational impact and evaluation studies for the governments of Denmark, The Netherlands, Belgium, Iceland, Hong Kong, and Norway. Amongst her numerous articles and book chapters, Anne is author of the "Wow Factor: Global Research Compendium on the Impact of the Arts in Education," which has been published in five languages and distributed in more than 40 countries. 